\title{
Measuring Neighbourhood Hardships and Neighbourhood Change between 2010-2015 in Suburban Neighbourhoods of Buffalo Metropolitan Area, New York
}

\author{
Ilhamdaniah Saleh $\mathrm{A}^{*}$ \\ Received: February 14, 2021 | Revised: May 26, 2021 | Accepted: May 27, 2021 \\ doi: 10.5937/gp25-30864
}

\begin{abstract}
Neighbourhoods in urban and suburban areas experienced changes in terms of physical, social, economic, and demographics. Neighbourhood Hardship Index (NHI) had been used to measure neighbourhood socio-economic condition, using various census variables. Suburban neighbourhoods which underwent a change lead to stratification into striving outer suburbs and declining inner suburbs. The context of this study was suburban neighbourhoods in Buffalo Metropolitan Area (BMA), New York. This paper aimed at highlighting spatial variability of neighbourhood change in inner- and outer-suburban neighbourhoods of BMA between 2010-2015. This study examined factors that significantly contribute to neighbourhood change. Also, this study examined whether there a difference in the change of neighbourhood hardship index between inner- and outer-suburban neighbourhoods. Composite NHI was developed from economic, demographic, and housing variables. Neighbourhood change was measured by comparing the composite $\mathrm{NHI} 2010$ with that of 2015. The findings depicted a variation of change in hardships index across suburban neighbourhoods. Neighbourhoods with higher hardship index were primarily located in inner suburbs. Policy implications call for concerted efforts to tackle the decline in the economy, education, demography to promote equity across neighbourhoods in suburban areas.
\end{abstract}

Keywords: suburban neighbourhood; neighbourhood change; suburban stratification; Neighbourhood Hardship Index

\section{Introduction}

\section{Suburban Neighbourhoods Transformation}

In the traditional metropolitan model, metropolitan areas consisted of an urban core and suburban ring. Distinctive socio-economic characteristics of neighbourhoods in urban and suburban areas lead to a dichotomy of urban and suburban neighbourhoods. Urban core or inner cities in the United States metropolitan areas are known for having distinctive differences with its suburbs in terms of physical, social, economic, and demographics aspects. Urban and sub- urban neighbourhoods experienced changes in terms of physical, social, economic, and demographics. As neighbourhoods changed, there was spatial variability of changes that occurs in urban and its surrounding suburban areas.

In recent discussions about the contemporary metropolitan model, the dichotomy of urban and suburban was criticized (Hanlon, 2006), suburban neighbourhood have diversified and became more heterogeneous (Hanlon et al., 2010). Suburban neigh-

\footnotetext{
A Department of Architecture, Faculty of Technology and Vocational Education, Universitas Pendidikan Indonesia, Indonesia

* Corresponding author: Ilhamdaniah Saleh, e-mail: ilhamdaniah@upi.edu
} 
bourhoods were also becoming heterogeneous and stratified due to the recent growth and decline of suburban neighbourhoods (Hanlon \& Vicino, 2019). Thus, the dichotomy of urban and suburban no longer holds true. Recent metropolitan development is beyond the urban-suburban dichotomy (Tzaninis \& Boterman, 2018). Suburban areas in the U.S. metropolitan areas are no longer monolith (Orfield, 2002). The growth and decline of suburban neighbourhoods create different trajectories among suburban neighbourhoods. Some suburban neighbourhoods thrive, especially the affluent outer-suburban neighbourhoods, while some other suburban neighbourhoods decline, mostly the older inner-suburban neighbourhoods. Suburban neighbourhoods underwent a change, which leads to stratification into declining inner suburbs and striving outer suburbs.

With the transformation and stratification of suburban neighbourhoods, another issue pertinent to suburban neighbourhood change in The United States is the discussion about suburban decline. Since America is a suburban nation with a majority of the population lives in the suburbs, the suburban decline is the next American urban crisis following the innercity crisis. The fact is since 2000, approximately $80 \%$ of Americans living in metropolitan areas, and $40 \%$ of suburban neighbourhoods are classified as "atrisk" (Orfield, 2002). Thus, this issue of suburban decline will have an impact on approximately $32 \%$ of the population in the nation, which is a very large population. The suburban decline is an imminent crisis face by American metropolitan areas after the inner city urban crisis (Lucy \& Phillips, 2000b). This suburban decline phenomenon had been investigated by urban scholars since early 2000 and gain more attention since then.

The trend of suburban decline is marked by its total population decline, out-migration from declining suburban neighbourhoods, and increasing poverty in suburban neighbourhoods. Inner-suburban population declines partly because their affluent inhabitants have left to outer-suburban or exurban neighbourhoods. Their motivation to move is related to their pursuance of a better job, housing, opportunities, public services, and neighbourhood conditions in the outer suburban neighbourhoods. There is an increasing poverty level in inner-suburban areas due to the out-migration of the middle-income class pursuing more opportunities in outer-suburbs and in-migration of the low-income population to inner-suburbs from the inner-city. This causes a dwindling tax base and an increasing poverty level. This pattern is prominent, especially in inner-ring suburban areas which share a border with the inner city.
Inner suburban neighbourhoods' decline is signaled by an increasing percentage of the population living in poverty. The suburbanization of low-income people from the inner city to suburban areas also increases poverty in suburban neighborhoods; this is recorded in the period of 1990-2000 (Berube et al., 2005). Suburban poverty is a centrifugal spin outward of poverty from the inner city to suburban neighbourhoods, especially inner suburban neighbourhoods. This triggers the decline of the inner-ring suburbs (Hanlon, 2010). The trend of growing suburban poverty also occurs in many metropolitan suburbs in the U.S. (Lucy \& Phillips, 2000a, 2000b, 2006).

Some suburban neighbourhoods experience a decline in relative income and dwindling tax-base to finance infrastructures and public services. The income distribution across U.S. metropolitan areas has shifted. The suburban areas, which were originally heralded as thriving, currently experience a decline in relative income. There is a trend of inter-suburban income disparities. From the sample of more than 2,500 suburban neighbourhoods in 35 metropolitan areas, half of the suburban areas had income below that of metropolitan level during the period of 1990-2000 (Lucy $\&$ Phillips, 2006). Suburban municipalities are often facing a downward spiral for not being able to sustain a sufficient level of public services due to a lack of a tax base (Hanlon, 2010).

In addition to the suburban neighbourhood decline issue, there is a racial composition shift that accompanied the process of inner-suburban decline. The outmigration from the inner-suburban to outer-suburban neighbourhoods is sometimes racially inclined. White-flight to more affluent suburban neighbourhoods. There is an influx of immigrants and racial minority groups in the inner suburbs. Racial and ethnic diversity is growing in suburban neighbourhoods. The influx of migration of immigrant and racial minority groups in suburban neighbourhoods creates racial and ethnic heterogeneity in suburban areas. The trend is showing an increasing percentage of Black, Hispanic/Latino, and Asian populations (ethnic minorities). Another way of framing the neighbourhood hardships, neighbourhoods change, and their variability was by using the lens of social inequity. Saleh (2020) relates neighbourhood change to the spatial inequity to access quality education in various suburban neighbourhoods. Neighbourhood change leads to spatial inequity of access to quality basic education between inner suburban neighbourhoods and outer suburban neighbourhoods. This study, alongside the paper on spatial inequity in accessing quality education in Buffalo Metropolitan Area, was part of a dissertation conducted by Saleh (2019). 


\section{Measuring Suburban Neighbourhoods}

Socio-economic Change and Its Hardship Level

To measure the change in neighbourhood socio-economic conditions, scholars can compare the hardship experienced by that particular neighbourhood. The hardship can be measured using a standardized index so that it can be compared. Changes in neighbourhood socio-economic conditions over a certain period of time can be measured by comparing the changes in the neighbourhood hardship index between the two years of measurements. Neighbourhood socio-economic condition assessment, in some cases, is measured using a standardized measure, called Neighbourhood Hardships Index (NHI) or Neighborhood Deprivation Index (NDI) (Messer et al., 2006). Neighbourhood socio-economic conditions are widely assessed using various variables in census data. This study attempted to measure the changes of socio-economic aspects of neighbourhoods over the period of 2010-2015 and compare the changes between the two neighbourhood location categories in the inner-suburban and outer-suburban neighbourhood context.

\section{Suburban Neighbourhoods \\ of Buffalo Metropolitan Area}

The context of this study was suburban neighbourhoods in Buffalo Metropolitan Area (BMA), New York, United States. There was a dichotomy between urban and suburban neighbourhoods of metropolitan Buffalo, followed by stratification of suburban neighbourhoods of the BMA. Thus, the suburban neighbourhood change is of particular interest in this study, particularly the stratification between inner- and outer suburban neighbourhoods. The declining innersuburban neighbourhoods and the disparity they have with the peer outer-suburban neighbourhoods is a focus of this study. The case study area to analyze suburban neighbourhood change in the declining metropolitan area was suburban neighbourhoods in Buffalo Metropolitan Area (BMA), New York, United States.

This paper aimed at highlighting spatial variability of neighborhood change in inner- and outer-suburban neighborhoods of the Buffalo Metropolitan Area between 2010-2015 by measuring the changes of values of standardized Neighbourhood Hardships Index between 2010 and 2015. Furthermore, this study compared the changes in NHI value experienced by innersuburban neighbourhoods and outer-suburban neighbourhoods. This study argued that there is a significant difference between inner- and outer-suburban neighbourhoods in terms of their suburban hardships index change. This discrepancy causes spatial inequity between the two suburban neighbourhood categories.

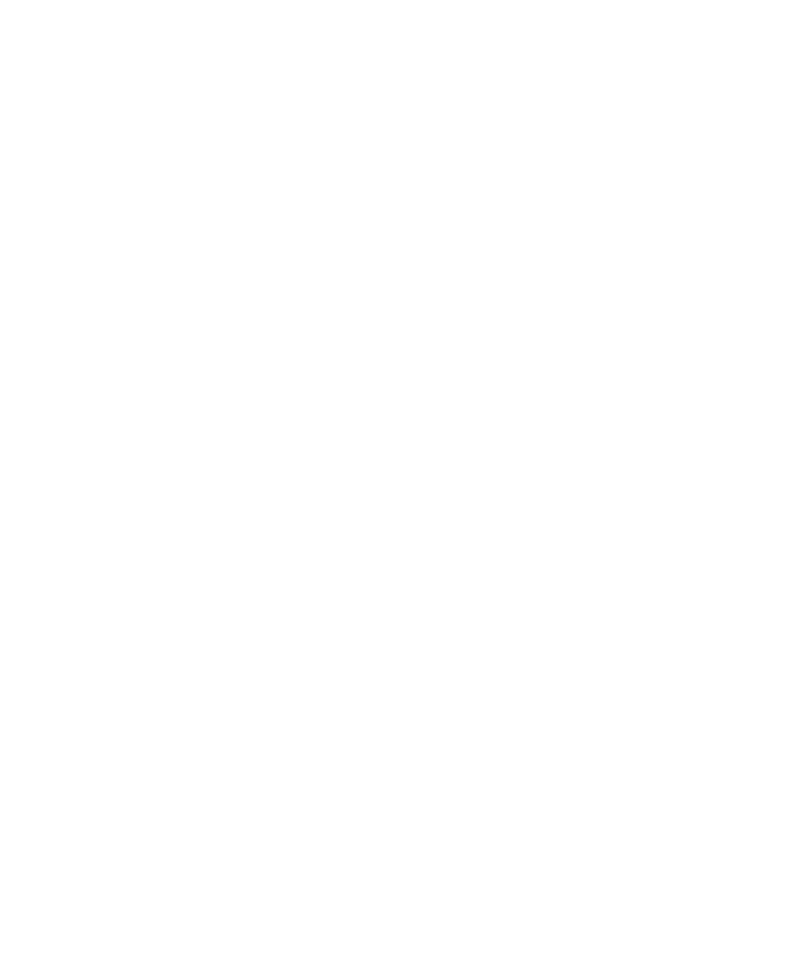

Figure 1. Study area: Buffalo Metropolitan Area, New York [click on figure to zoom]

This study was important to be conducted because there is a lack of understanding of the suburban neighborhood change phenomenon in the context of the declining metropolitan area, like the Buffalo Metropolitan Area. Previous literature on suburban neighbourhood change mostly sampled 1639 suburban neighborhoods of 13 metropolitans of big cities in the U.S. (Hanlon et al., 2006), which did not include declining metropolitan areas. Hanlon et al. (2006) suggested the need for subtler frameworks to analyze suburban neighbourhoods to understand the structure of contemporary metropolitan areas.

There is a need to study suburban neighborhood change in the context of a declining city in the U.S., such as Buffalo. Therefore, this study is significant to be conducted for several reasons, among those are: 1) the growing percentage of suburban poverty and suburban decline will be the next urban crisis and will affect a very large number of population in the nation if left unaddressed, 2) the current suburban change (socio-economic shift coupled with school socio-economic shift) affects current school performance and future neighborhood's likelihood to grow. 3) the spatial inequity of suburban neighborhood quality, educational opportunities, and educational outcomes between suburban neighborhoods, if left unaddressed, can lead to more debilitating impacts and social costs in the future. 


\section{Review of Methods}

\section{to Measure Neighbourhood Change}

The change of suburban neighbourhood changes (growth/decline) can be measured by calculating absolute change and relative change. The results of measurement of suburban decline using both methods should be complementary to each other. The utilization of absolute change to measure suburban decline was conducted by several studies (Lucy \& Phillips, 1997, 2001). Both studies incorporate variables from sociodemographic of the suburban area, e.q. population, population density, housing, employment; but use relative income measurement. The utilization of relative change and construction of index to measure suburban decline was introduced in the study of Orfield (1997) and Hanlon (2008). Both studies incorporate variables from sociodemographic of the suburban area and use ratio or relative income measurement.

Variables to construct an index of suburban decline in Orfield (1997) include the percentage of femaleheaded households, the percentage of children less than five years old in poverty, relative median household income, and household tax. In Hanlon (2008), the variables to construct an index of suburban decline were changes in population size, changes in relative median household income, and changes in poverty. However, the difference lies in the denominator of the relative income variable in those two studies. In Orfield (2007), the relative income of a suburban neighbourhood was measured in ratio to the overall metropolitan area, while in Hanlon (2008), the relative income of a suburban neighbourhood was compared to overall suburban areas. Mikelbank (2006) also investigated the change of suburban within the metropolitan context by using the relative measure.

However, different from Orfield and Hanlon, who used the index to measure decline, Mikelbank only used population change as an example. He used the location quotient (L.Q.) to measure the change of population in suburban areas. A relative measure of the population in 2000 was measured by making the ratio between a certain suburban population in 2000 with the overall metropolitan population in 2000. A relative measure of the population in 1990 was measured by making the ratio between a certain suburban population in 1990 with the overall metropolitan population in 1990. Furthermore, L.Q. of a certain suburban neighbourhood is the ratio between the relative population in 2000 and relative population in 1990.

Based on this review of methods to measure neighbourhood change, this study measured neighbourhood change between $2010-2015$ by utilizing absolute change and incorporating variables from sociodemographic of the suburban areas. This study constructed an index to measure suburban neighbourhood change and suburban decline between the two measurement years.

\section{Data and Analysis}

The data source was derived from American census data, called the American Community Survey (ACS) in the year 2010 (ACS, 2010) and the year 2015 (ACS, 2015). Census data was retrieved at the blockgroup level for suburban neighbourhoods in the BMA. Block-groups are categorized based on their location, whether they are located in inner-suburban neighborhoods or outer-suburban neighbourhoods.

This study hypothesized that there is a significant difference in neighborhood hardships between innerand outer-suburban neighborhoods. To prove that hypothesis, the following analysis steps were undertaken. The analysis comprises of the descriptive analysis of suburban neighborhoods and suburban neighborhood change. The descriptive part depicted the variables that shape suburban neighborhoods, which are grouped in population, economic, social, and housing aspects. The suburban change section was elaborated by the following structure: 1) measurement of neighborhood deprivation index in 2010 and 2015, 2) measurement of the suburban neighborhood change that occurred between 2010-2015, and 3) identification of the differences in the trajectory of neighborhood change between inner-suburban neighborhoods and outer-suburban neighborhoods.

Neighborhood change was calculated by measuring the change of Neighborhood Hardship Index (NHI) between two measurement years, which are 2010 and 2015. Neighborhood hardship index in 2010 and 2015 need to be calculated prior to calculating the neighborhood change between the two periods of measurements. The neighbourhood hardship index for each year of measurement is calculated by incorporating a set of 12 census variables, namely population number, the percentage of White, the percentage of African-American (Black), the percentage of Hispanic, the percentage of female-headed household with children, the percentage of people with education attainment more than high school graduates, the percentage of the population in poverty, the household income, the unemployment rate, the percentage of owner-occupied housing, the percentage of vacant housing, and the median housing value of owner-occupied housing. Those census variables used were reflecting the five urban social domains, namely: (1) income, (2) labor 
force, (3) housing, (4) demographic, and (5) education. Those contributing variables were undergone a Principal Component Analysis (PCA) to determine which factors most contribute to the change and identified as components that contributed to suburban neighbourhood change.

\section{Results}

First of all, this study examined factors contributing to the Neighbourhood Hardship Index of suburban neighbourhoods in 2010 and 2015. Secondly, this study measured suburban neighbourhood change between 2010-2015 experienced by two categories of suburban neighbourhoods, namely inner-suburban and outer-suburban neighbourhoods. Thirdly, this study conducts analysis to support the argument that there is a significant difference between the change in Neighbourhood Hardship Index in the period of 2010-2015 between inner suburban neighbourhoods and outer suburban neighbourhoods. The findings of the study are described in the following.

\section{The Contributing Factors}

\section{of Neighbourhood Hardship Index}

The Principal Component Analysis (PCA) was performed in this study to examine which variable has a higher impact on the hardship index. PCA accounted for the inter-correlation among sociodemographic variables. PCA eliminates the issue of multicollinearity among various variables used to identify neighbourhood hardships change. Prior calculation of standardized score of Neighbourhoods Hardship Index (NHI) treated each variable as equal without giving different weight for several variables that are considered more important affecting NHI. Descriptive analysis and standardizing scores also did not consider the inter-correlation or multicollinearity among variables. PCA was performed to address this issue. PCA was also beneficial in reducing the number of variables and grouped them into several groups that possess similar characteristics, further called a component. PCA used the Varimax rotation method. PCA produced five (5) components representing $61 \%$ of the total variance. The component loadings are presented in Table 1 . The components, the Eigen-values, and the total variance explained are shown as well.

PCA was successful in elaborating components (a group of factors) affecting neighbourhood change in BMA. Table 1 informs that overall, five (5) components extracted from PCA could explain $61.15 \%$ of the total variance in neighbourhood change. Based on the percentage of variance explained by each component, neighbourhood change was contributed by the change in racial composition (15.13\%), poverty and family structure (14.28\%), housing ownership and value (11.23\%), income and belonging (10.51\%), and education and employment (10.00\%).

Table 1. The components and their explanatory power

\begin{tabular}{|l|l|l|c|c|c|}
\hline Components & Component Name & Variables loaded to component & Eigen-value & $\begin{array}{c}\% \text { Total } \\
\text { Variance }\end{array}$ & $\begin{array}{c}\text { Cumulative } \\
\%\end{array}$ \\
\hline Component 1 & $\begin{array}{l}\text { Racial composition } \\
\text { change }\end{array}$ & $\begin{array}{l}\text { The change in the percentage of } \\
\text { White, change the percentage of } \\
\text { Black }\end{array}$ & 1.816 & 15.130 & 15.130 \\
\hline Component 2 & $\begin{array}{l}\text { Poverty and family } \\
\text { structure change }\end{array}$ & $\begin{array}{l}\text { The change in the percentage of } \\
\text { of female-headed household, and } \\
\text { change in the percentage of the } \\
\text { population in poverty }\end{array}$ & 1.714 & 14.279 & 29.409 \\
\hline Component 4 & $\begin{array}{l}\text { Housing ownership } \\
\text { and vacancy } \\
\text { change }\end{array}$ & $\begin{array}{l}\text { Change in percentage of owner- } \\
\text { occupied housing and change in the } \\
\text { percentage of vacant housing }\end{array}$ & 1.348 & 11.232 & 40.641 \\
\hline Colonging & $\begin{array}{l}\text { Change in household income and } \\
\text { change in median housing value of } \\
\text { owner-occupied housing }\end{array}$ & 1.262 & 10.513 & 51.154 \\
\hline
\end{tabular}




\section{Components Contributing to Suburban} Neighbourhoods Change in Buffalo Metropolitan The GIS maps illustrated the variables that contribute to neighbourhood change to delve into details of factors contributing to the neighbourhood change elaborated in Table 1. The distribution of neighbourhood undergone changes was presented consecutively in Figure 2, Figure 3, and Figure 4. The top three components that contribute to neighbourhood change are: (1) the change in racial composition, (2) poverty and family structure, (3) housing ownership and vacancy. The suburban neighbourhood delineation between inner-suburban and outer-suburban neighbourhood was also drawn in the map to better observe the different trajectories of change between the two suburban neighbourhood categories.

Based on the distribution of neighbourhoods undergone a decline in the percentage of the White population, it is observed that inner-suburban neighbourhoods experience more decline in the White population. The white population tends to leave inner suburban neighbourhoods to more affluent outer-suburban neighbourhoods or newer suburbs. From Figure 2, it is also observed that the suburban neighbourhoods located in the northeastern part of Buffalo Metropolitan Area were experiencing a declining percentage of the White population, who moved out- ward from outer-suburban neighbourhoods that are bordering inner-suburban neighbourhoods.

Figure 3 depicts that inner-suburban neighbourhoods experience more change in poverty level. Inner-suburban neighbourhoods bordering inner-city Buffalo are experiencing an increase in the percentage of the population in poverty. The high percentage of the population living in poverty in the city of Buffalo spills over to its neighbouring inner suburbs.

Figure 4 illustrated that more neighbourhoods in inner-suburban neighbourhoods also experienced an increase in the percentage of vacant housing. An increase in the percentage of vacant housings in the neighbourhood is a signal of declining neighbourhoods. More vacant housings in the neighbourhoods indicate that people are leaving the neighbourhoods, and furthermore, the vacant houses in the neighbourhood are left unmaintained.

\section{Geographic Pattern of Suburban Neighbourhoods Change in Buffalo Metropolitan Area}

Figure 5 corresponded to the overall calculation of suburban neighbourhoods change between 2010-2015 in Buffalo Metropolitan Area. If the hardships index in 2015 is higher than the hardship index in 2010 (changes in index value between 5-25), that neighbourhood is considered as declining. If the hardships index in 2015
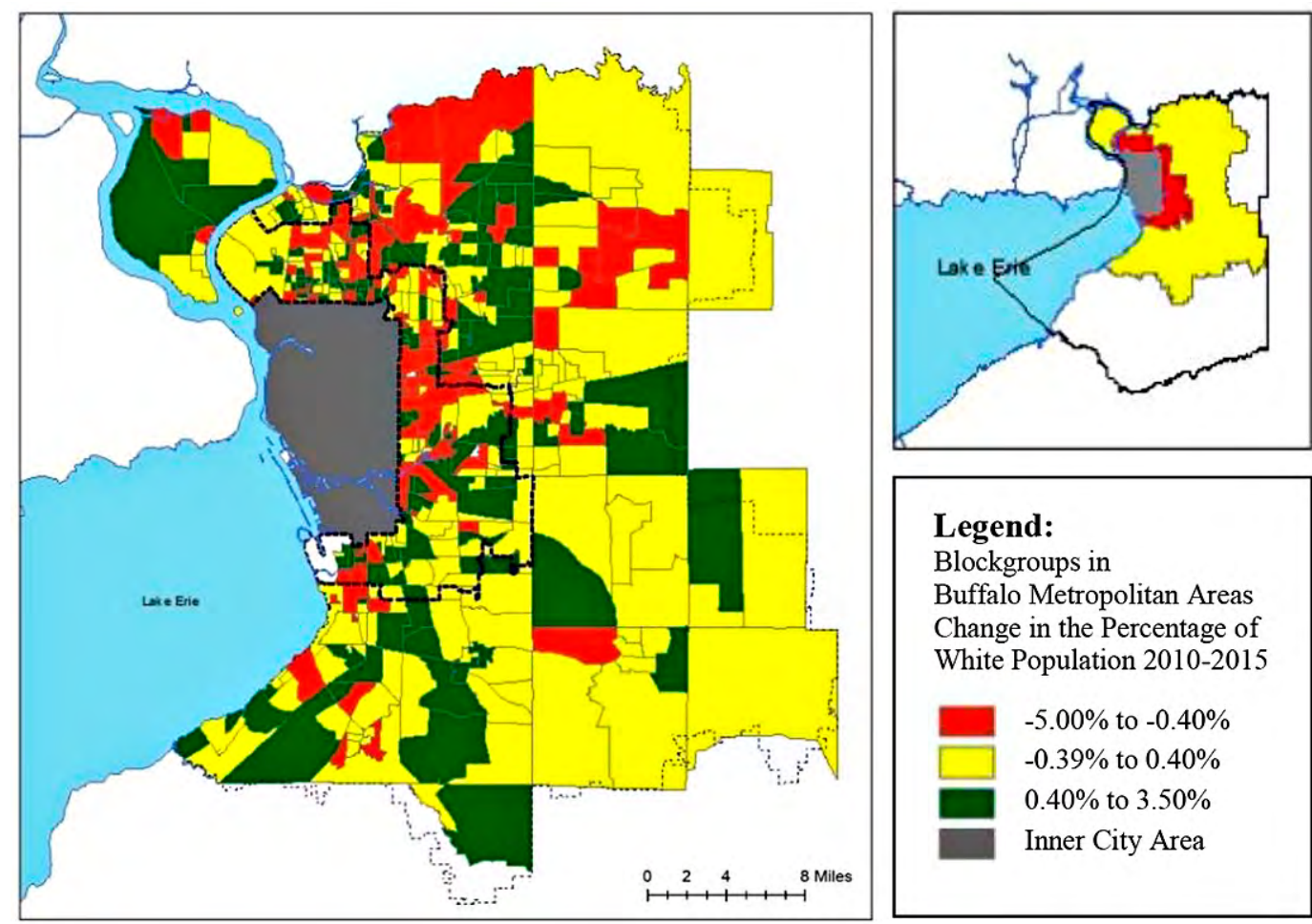

Legend:

Blockgroups in

Buffalo Metropolitan Areas

Change in the Percentage of

White Population 2010-2015

$-5.00 \%$ to $-0.40 \%$

$-0.39 \%$ to $0.40 \%$

$0.40 \%$ to $3.50 \%$

Inner City Area

Figure 2. The first component contributing to Neighbourhood Change between 2010-2015

(The change in racial composition: White population) 

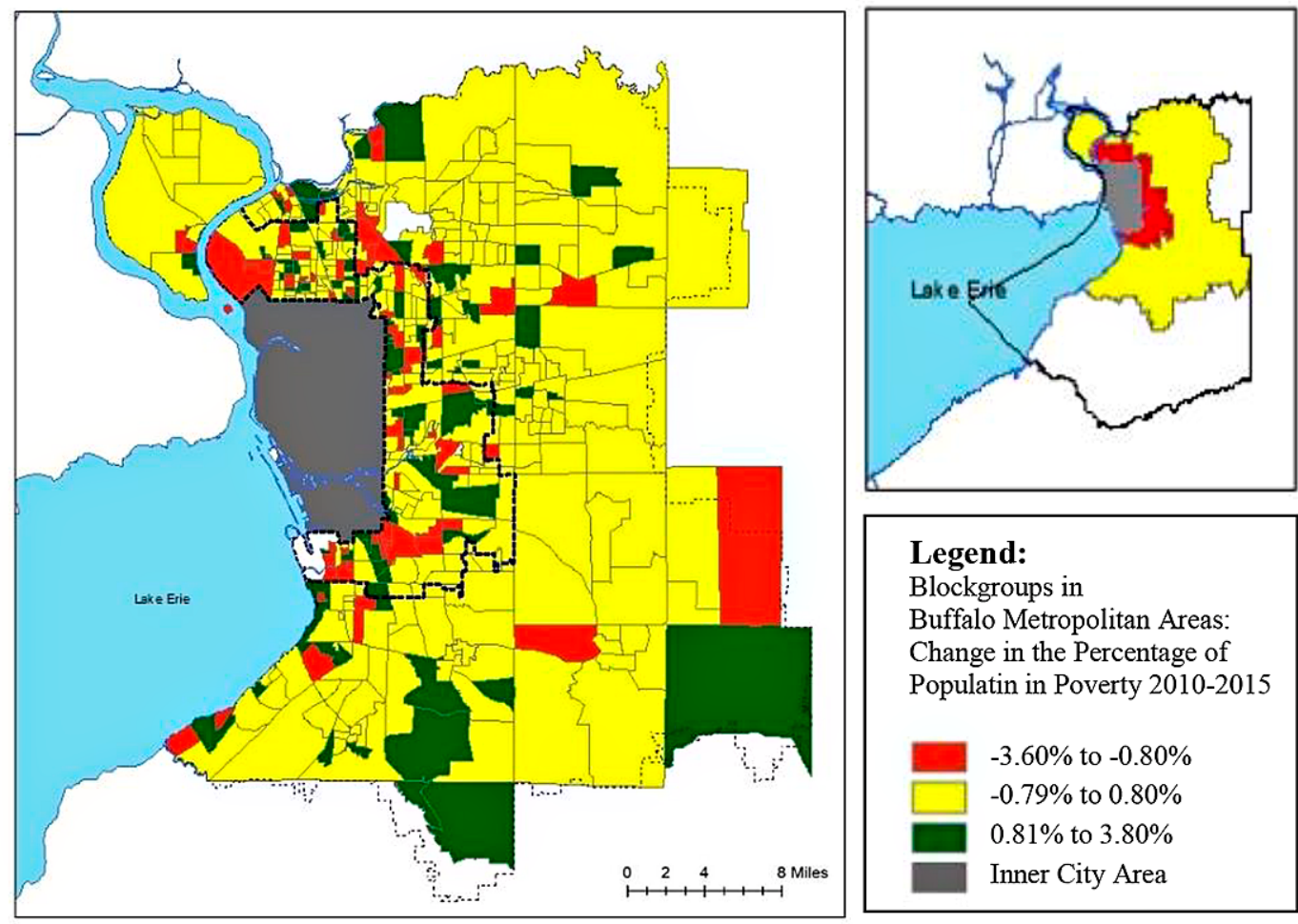

Legend:

Blockgroups in

Buffalo Metropolitan Areas:

Change in the Percentage of

Populatin in Poverty 2010-2015

Figure 3. The second component contributing to Neighbourhood Change between 2010-2015 (The Percentage of Population in Poverty)

is approximately the same as the hardship index in 2010 (changes in index value between $0-5$ ), that neighbourhood is considered stable. However, if the hardships index in 2015 is lower than the hardship index in 2010 (changes in index value between 0 to -20 ), that neighbourhood is considered as improving. The spatial distribution of block-groups that experienced a decline, remain stable, and improved was depicted in that figure.
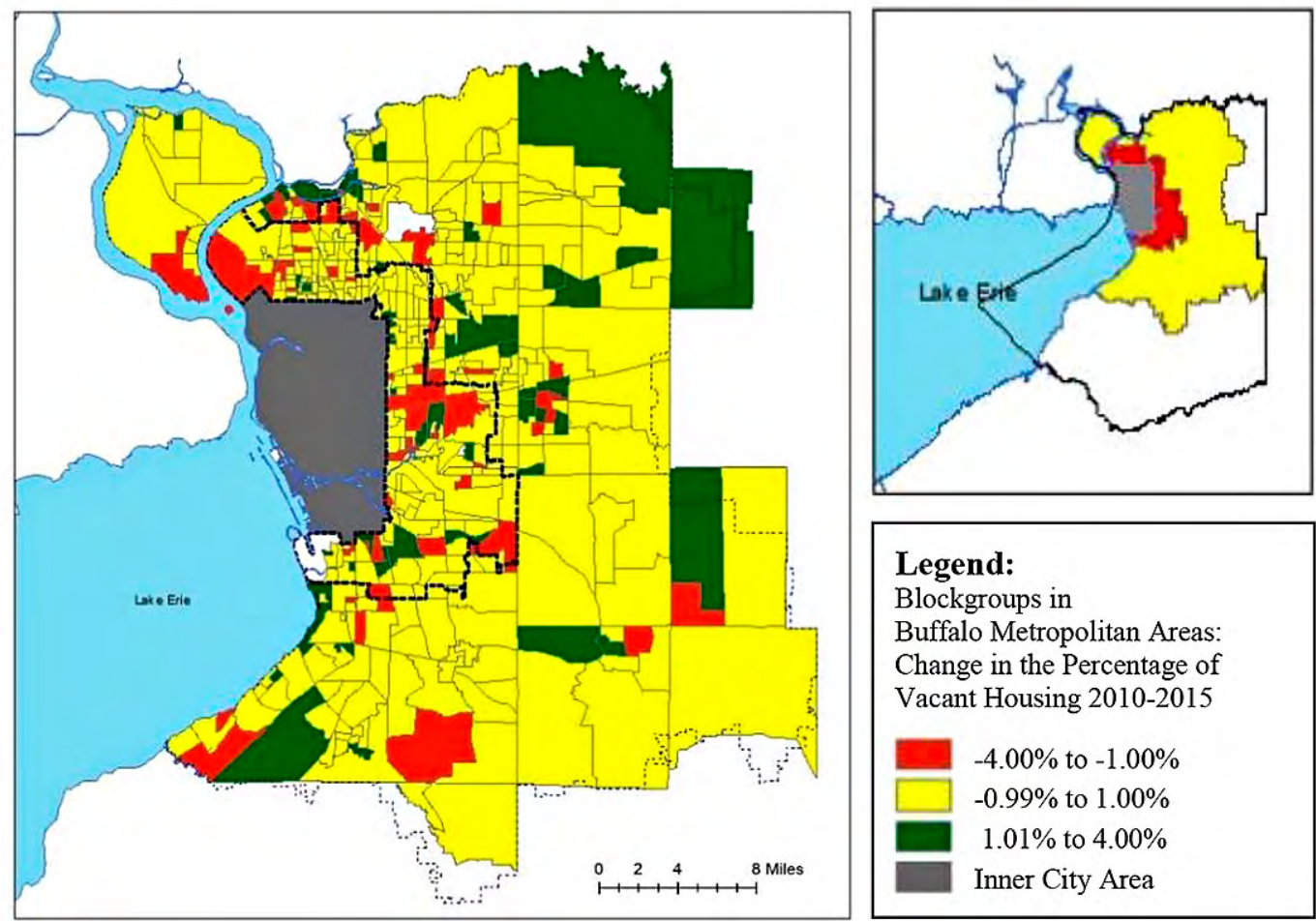

\section{Legend:}

Blockgroups in

Buffalo Metropolitan Areas:

Change in the Percentage of

Vacant Housing 2010-2015

$-4.00 \%$ to $-1.00 \%$

$-0.99 \%$ to $1.00 \%$

$1.01 \%$ to $4.00 \%$

Inner City Area

Figure 4. The third component contributing to Neighbourhood Change between 2010-2015 (The Percentage of Vacant Housing) 


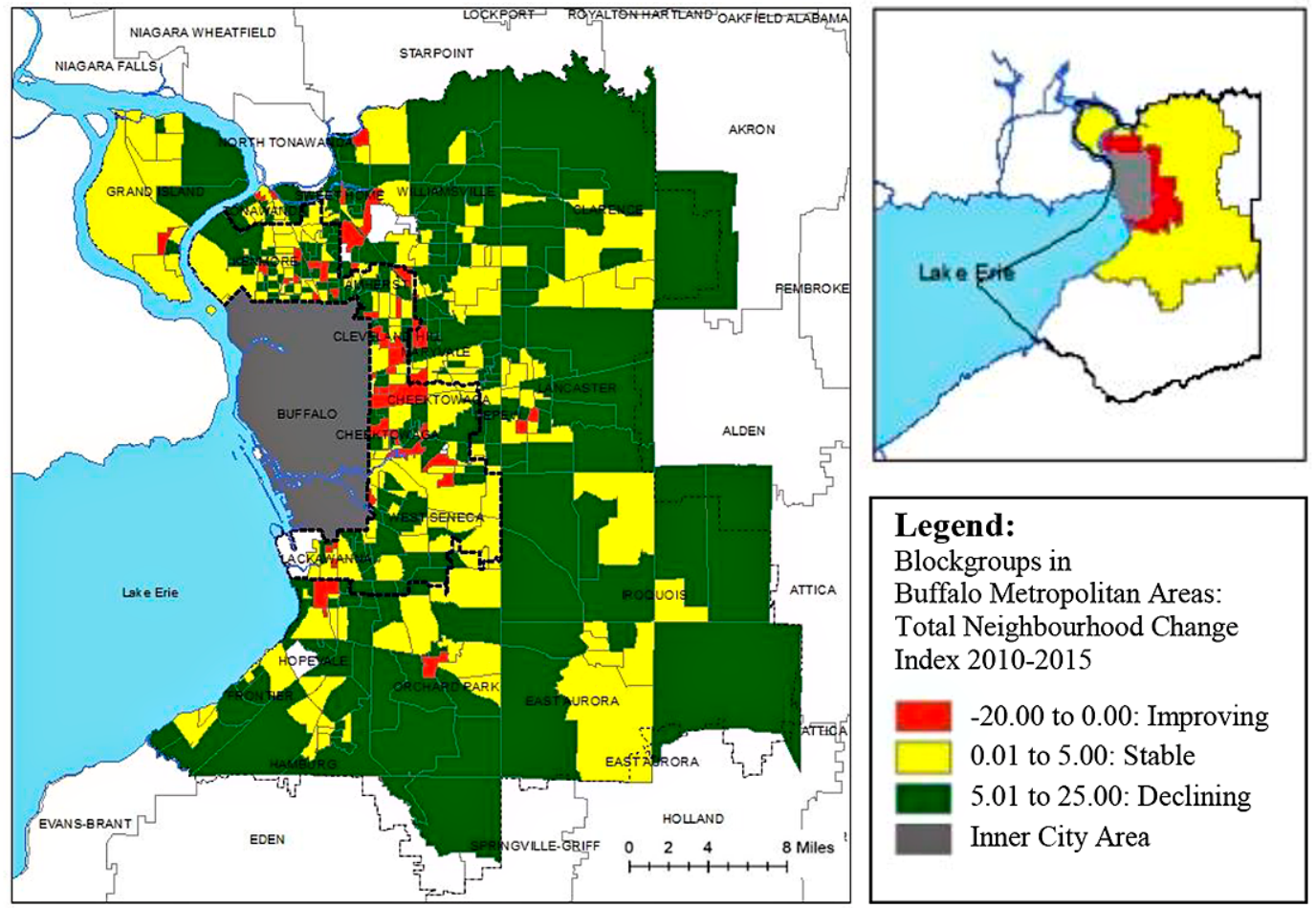

Figure 5. Overall Neighbourhood Change Index between 2010-2015

Declining block-groups (illustrated by red colour in the map in Figure 5) were mostly located in innersuburban neighbourhoods. Those inner-suburban block groups were located in Kenmore, Cleveland Hill, Cheektowaga, and Lackawanna. Most block-groups in outer-suburban experienced improvement and stability, except for some small number of block-groups in Sweet Home near University at Buffalo North Campus, Depew, Orchard Park, and Frontier neighbouring Lackawanna. Figure 5 also highlights low socio-economic-status neighbourhoods in inner-suburban that experienced a decline. Those block groups were located in Cheektowaga neighbourhoods. Suburban neighbourhoods that experience improvement (illustrated by green colour in the map) between 2010-2015 were mostly located in outer-suburban neighbourhoods. This illustration shows that there is a pattern of suburban neighbourhood change in the Buffalo metro- politan. Furthermore, this GIS map also supports the hypothesis that there is a difference in the trajectory of neighbourhood change between inner-suburban neighbourhoods and outer-suburban neighbourhoods.

In addition to that, a statistical analysis (T-test analysis) was also conducted to support the hypothesis that there is a statistically significant difference in Neighbourhood Hardship Index between inner-suburban neighbourhoods and outer-suburban neighbourhoods. The result of statistical T-test analysis shows that there is a significant Neighborhood Hardship Index (NHI) difference between inner and outer suburban in 2010. However, the T-test analysis for the year 2015 shows that there is not a significant difference in NHI in 2015. This means that outer-suburban neighbourhoods started to have similar values of hardship index with the inner-suburban neighbourhoods.

\section{Conclusion}

Based on the findings and discussions, it was identified that suburban neighbourhoods decline occurred in older suburbs of inner-ring suburban Buffalo Metropolitan Area. This study also showed a pattern of decline in inner-suburban neighborhoods of BMA, just as mentioned in previous studies of the decline of older suburbs or inner-ring suburbs in metropolitan America (Hanlon, 2008, 2010; Hanlon \& Vicino, 2007; Short et al., 2007). This also followed the patterns of suburban growth and decline (Lucy \& Phillips, 1997, 2001). However, this study also found the pattern of suburban neighbourhoods which experience improvement. Outer suburban neighbourhoods experienced ascent in their socio-economic condition and descent in their neighbourhood hardship index. This phenomenon also occurred in other metropolitan areas in the U.S. Different trajectories of neighbourhoods change is a source of inequality, and neighbourhood 
Table 2. The highlight of the difference between inner and outer suburban neighborhoods

\begin{tabular}{|c|c|c|}
\hline Aspect & Inner-suburban & Outer-suburban \\
\hline \multicolumn{3}{|c|}{ Neighborhood change } \\
\hline $\begin{array}{l}\text { Neighborhood } \\
\text { demographics }\end{array}$ & $\begin{array}{l}\text { More diversity. More racial minority groups in } \\
\text { Lackawanna (South), Cheektowaga Central (West), } \\
\text { Cleveland Hill (West). }\end{array}$ & $\begin{array}{l}\text { There is less diversity in most outer suburban } \\
\text { neighbourhoods, especially in southern outer } \\
\text { suburban neighbourhoods. Diversity in outer- } \\
\text { suburban neighbourhoods occurred in the } \\
\text { northeastern part of suburban BMA (Sweet Home, } \\
\text { Williamsville). }\end{array}$ \\
\hline \multirow[t]{2}{*}{$\begin{array}{l}\text { Neighborhood } \\
\text { hardships }\end{array}$} & $\begin{array}{l}\text { The higher mean of neighbourhoods hardship index } \\
\text { in inner suburban means inner suburban block- } \\
\text { groups are experiencing more adversities. }\end{array}$ & $\begin{array}{l}\text { Outer suburbs have a lower mean of } \\
\text { neighbourhoods hardship index. Fewer hardships } \\
\text { are experienced by most outer suburban block } \\
\text { groups. }\end{array}$ \\
\hline & \multicolumn{2}{|c|}{$\begin{array}{l}\text { Based on statistical analysis (T-test analysis), there is a significant Neighborhood Hardship Index (NHI) } \\
\text { difference between inner and outer suburban in } 2010 \text {, but not a significant difference of } \mathrm{NHI} \text { in } 2015 \text {. This } \\
\text { means that outer-suburban neighbourhoods started to have similar values of hardship index with the } \\
\text { inner-suburban neighbourhoods. }\end{array}$} \\
\hline \multirow[t]{2}{*}{$\begin{array}{l}\text { Change of } \\
\text { neighborhood } \\
\text { hardships }\end{array}$} & $\begin{array}{l}\text { Most declining block groups are located in inner } \\
\text { suburban neighbourhoods. The block groups } \\
\text { clustered in Cheektowaga, West Seneca, Kenmore- } \\
\text { Tonawanda. }\end{array}$ & $\begin{array}{l}\text { There are enclaves of block-groups experiencing a } \\
\text { decline in outer suburban neighbourhoods of Sweet } \\
\text { Home scattered near University. A small enclave } \\
\text { of declining block-groups in Grand Island, Depew, } \\
\text { Orchard Park, and Frontier. }\end{array}$ \\
\hline & \multicolumn{2}{|c|}{$\begin{array}{l}\text { Both suburban neighbourhood categories experience change (grow, stable, and decline). However, } \\
\text { declining block groups are more prevalent in inner-suburban neighbourhoods, while socio-economically } \\
\text { ascending block-groups are more prevalent in outer-suburban neighbourhoods. }\end{array}$} \\
\hline
\end{tabular}

change may lead to changing opportunities for residents (Owens, 2012). This study also depicts suburban neighbourhoods of BMA are becoming more heterogeneous in terms of socio-economic condition.

The highlight of the difference between inner and outer suburban neighbourhoods in the Buffalo Metropolitan Area is depicted in Table 2.

This study adds to a prior study of the suburban neighbourhood change in the Buffalo Metropolitan Area. Previously, Buffalo suburban neighbourhood change was studied only as part of nationwide metropolitan areas research between 1990-2000 (Lucy \& Phillips, 2001, 2003). In those two prior studies, two observations were made: 1) Buffalo metropolitan area lost population during the 1990s (-1.6\%), and 2) Buffalo metropolitan had a high percentage of suburban neighbourhood's decline (71.4\%). The study findings also add to that information about Buffalo Metropolitan Area suburban change timeline between 20102015. First, during the study timeframe of 2010-2015, overall BMA showed stable population growth, with some suburban neighbourhoods experienced a decline in population while other suburban neighbourhoods experienced a gain in total population. Most inner-suburban neighbourhoods lost their population (mean of change of total population $=-1.15 \%$ ), but most outer-suburban neighborhoods gain population (+2.84\% change of total population). Second, during the period of 2010-2015, Buffalo suburban neighbourhoods had a lower percentage of suburban neighbour- hood decline as opposed to Lucy and Phillips' findings in the timeframe 1990-2000.

Our findings of this study also elaborate in more detail about the characteristics of suburban decline in Buffalo suburbs. Early work by Lucy and Philips (2001, 2003) stated that the suburban decline in BMA was very high, with $71.4 \%$ of suburban neighbourhoods being studied undergone decline. However, Lucy and Phillips (2001, 2003) did not dichotomize suburban neighbourhoods into two categories of inner-ring and outer-ring Buffalo suburban neighbourhoods. The findings of this study add to that knowledge by describing that the decline has occurred mostly in inner suburban neighbourhoods. In addition to that, the percentage of suburban neighbourhoods decline was lower during 2010-2015. The result of the study also in line with the current debate on suburban dynamics, that there is strong evidence of variation within the suburbs themselves. There is great variation along the urban/suburban spectrum, and the socio-economic characteristics of inner suburbs are more like urban areas than they are like outer suburbs (Airgood-Obrycki, Hanlon, \& Rieger, 2020).

With the utilization of Geographic Information System (GIS), this study also illustrated the spatial distribution of suburban neighborhoods which are declining, stable, or growing. In addition to that, the utilization of GIS visualization in the study also had pinpointed the spatial distribution of inner-suburban neighbourhoods that experienced a decline. That adds to the knowledge 
to understand the structure of contemporary declining metropolitan areas, especially in the case of Buffalo Metropolitan Areas. The result of this study suggests that suburban neighbourhoods change happening in Buffalo Metropolitan Areas, and this suggests more studies to examine whether this has wider significance and this phenomenon is also happening in other declining metropolitan areas in the United States.
This study recommends further analysis of suburban neighbourhood changes in metropolitan areas which experience a decline in the past decades, such as metropolitan areas located in Rust Belt areas in the northeastern region of the United States. This will add to our understanding of the structure of contemporary declining metropolitan areas in the northeastern region of the United States.

\section{Acknowledgment}

The author would like to thank Prof. Robert Silverman and Prof. Li Yin (School of Architecture and Planning, The State University of New York at Buffalo, United States) for their supervision during the research phase.

This article publication funding was supported by the National Research and Innovation Agency of the Ministry of Research and Technology of the Republic of Indonesia, for Research and Community Service Institution (LPPM) Universitas Pendidikan Indonesia, grant number 458/UN40.D/PT/2020.

\section{References}

Airgood-Obrycki, W., Hanlon, B., \& Rieger, S. (2020). Delineate the U.S. suburb: An examination of how different definitions of the suburbs matter. Journal of Urban Affairs, 1-22. doi: 10.1080/07352166.2020.1727294

Berube, A., Katz, B., \& Lang, R. E. (Eds.). (2005). Redefining Urban and Suburban America: Evidence from Census 2000 (Vol. 2). Washington D.C.: The Brookings Institution.

Hanlon, B., Vicino, T. J., \& Short, J. R. (2006). The New Metropolitan Reality in the US: Rethinking the Traditional Model. Urban Studies, 43(12), 21292143.

Hanlon, B., \& Vicino, T. J. (2007). The Fate of Inner Suburbs: Evidence From Metropolitan Baltimore. Urban Geography, 28(3), 249-275. doi: 10.2747/02723638.28.3.249

Hanlon, B. (2008). The Decline of Older, Inner Suburbs in Metropolitan America. Housing Policy Debate, 19(3), 423-455.

Hanlon, B. (2010). Once the American Dream: Inner-Ring Suburbs of the Metropolitan United States. Philadelphia: Temple University Press.

Hanlon, B., Short, J. R., \& Vicino, T. J. (2010). Cities and Suburbs: New Metropolitan Realities in the U.S. New York: Routledge: Taylor and Francis Group.

Hanlon, B., \& Vicino, T. J. (2019). The Routledge Companion to the Suburbs (B. Hanlon \& T. J. Vicino Eds.). New York: Routledge.

Saleh, I. (2019). Suburban Neighborhood Change and Its Manifestation in the Disparities in Neighborhood Hardship, Educational Opportunity, and School Performance between 2010 and 2015 in the Buffalo Met- ropolitan Area. (Doctoral Dissertation), The State University of New York at Buffalo, Buffalo, New York.

Lucy, W. H., \& Phillips, D. L. (1997). The Post-suburban Era Comes to Richmond: City Decline, Suburban Transition, and Exurban Growth. Landscape and Urban Planning, 36, 259-275.

Lucy, W. H., \& Phillips, D. L. (2000a). Confronting Suburban Decline: Strategic Planning for Metropolitan Renewal. Washington D.C.: Island Press.

Lucy, W. H., \& Phillips, D. L. (2000b). Suburban Decline: The Next Urban Crisis. Issues in Science and Technology, 17(1), 55-62.

Lucy, W. H., \& Phillips, D. L. (2001) Suburbs and the Census: Patterns of Growth and Decline. Center on Urban \& Metropolitan Policy: Brookings Institution.

Lucy, W., \& Phillips, D. L. (2003). Suburbs: Patterns of Growth and Decline. In A. Berube, B. Katz, \& R. Lang (Eds.), Redefining Urban and Suburban America: Evidence from Census 2000 (Vol. 1). Washington D.C.: Brookings Institution Press.

Lucy, W. H., \& Phillips, D. L. (2006). Tomorrow's Cities, Tomorrow's Suburbs. Chicago: American Planning Association.

Mikelbank, B. A. (2006). Local Growth Suburbs: Investigating Change within the Metropolitan Context. Opolis, 2(1), 1-15.

Orfield, M. (1997). Metropolitics: A Regional Agenda for Community and Stability. Washington D.C.: Brookings Institution.

Orfield, M. (2002). American Metropolitics: The New Suburban Reality. Washington D.C.: Brookings Institution Press. 
Owens, A. (2012). Neighborhoods on the Rise: A Typology of Neighborhoods Experiencing Socioeconomic Ascent City \& Community, 11 (4), 345-369

Saleh, I. (2020). Neighborhoods Drifting Apart: Suburban Neighborhood Stratification and Its Impact on Spatial Inequity of Access to quality Schools in Suburban Neighhborhoods of Buffalo Metropolitan Area, New York. Paper presented at the In- ternational Seminar of Research for Social Justice, Bandung.

Short, J. R., Hanlon, B., \& Vicino, T. J. (2007). The Decline of Inner Suburbs: The New Suburban Gothic in the United States. Geography Compass, 1(3), 641-656.

Tzaninis, Y., \& Boterman, W. (2018). Beyond the urban-suburban dichotomy. City, 22(1), 43-62. doi: 10.1080/13604813.2018.1432143 